Original Research

\title{
Influencing Factors Analysis for Distribution Pattern of Town Green Space Planning: Perspectives Acquired from Three Towns in Xinzheng, Henan, China
}

\author{
Pengfei Zhang, Qiusheng Yang* \\ College of Landscape Architecture and Art, Henan Agricultural University, Zhengzhou 450002, China
}

Received: 29 September 2020

Accepted: 5 December 2020

\begin{abstract}
Uneven green space distribution may lead to environmental injustice. This study includes three Chinese towns to explore quantitative method of uniform distribution of urban green space in combination with Gini Coefficient theory. Three quantitative indices have been used to analyze green space planning distribution pattern. The indices reveal horizontal and vertical distribution patterns of green space in these three towns. Distribution pattern of green space composite structure of Hezhuang town is very uneven, distribution pattern of the green space composite structure of Xuedian town is reasonably even, and distribution pattern of the green space composite structure of Lihe town is absolutely even. Based on a contrastive analysis, four conclusions and one recommendation have been drawn. This paper improves the understanding of factors influencing the distribution patterns of town green spaces by providing a basis for judgment of urban environmental equity and a reference for more equitable green space planning.
\end{abstract}

Keywords: green space distribution, landscape architecture, land utilization, urban and rural planning, Gini coefficient

\section{Introduction}

Green spaces form ecosystems and provide ecological services, and operation of a city depends on its external natural ecosystem and its internal ecosystem. Urban green spaces benefit the body and physiology of town inhabitants [1-4]. By providing

*e-mail: 1992442715@qq.com

a place for physical exercise and gatherings, green spaces cater aesthetic pleasure and leisure opportunities for the citizens [5]. Urban vegetation has also been shown to impact the quality of life and improve mental health of citizens [6-8]. Dzhambov and Dimitrova [9] have provided an increasing evidence of a positive relation between green spaces in peoples living environment and self-reported indicators of physical and mental health.

It has been shown that when planned coherently, urban green spaces have the potential to provide a range 
of unique ecosystem services for cities which support ecosystem and human health [10-16]. At an individual level, community gardens is a more attractive destination for community walking by providing a venue for physical activity, a place for gardening and a comfortable environment in the form of a restorative space. At the community level, gardens can promote interaction between different social groups and provide unique environmental education opportunities that lead to the improvement of local ecological efficiency.

Tsai, et al. [17] have researched land cover types and landscape metrics in the context of psychological health of the citizens of 276 U.S. counties and conclude that greater edge contrast has a bearing on $3.81 \%$ lower odds of Frequent Mental Distress (FMD) and shrubland cohesion and distance between shrubland cover have a bearing on greater odds of FMD. Rautio et al. [18] has explored original studies prior to October 2016 by taking advantage of databases of PubMed, Scopus and Web of Science for population-based and found that the shortage of green space was more clearly associated with depressive mood even after adapting to different individual characteristics. Similarly, according to 2009 Korean Community Health Survey data, Min et al. [19] investigated the association between parks and green areas with the risk for depression or suicidal indicators among adults and the results show that compared to adults who live in the most parks and green spaces, those who live in areas with the fewest parks and green spaces had $16-27 \%$ greater odds for depression and suicidal indicators, after correcting all the potential variables [19]. In addition, more urban green space is proportional to fewer occurrences of mental health complaints. Similarly, Zhang et al. [20] has proposed framework that links green spaces to public health and suggested that a clear health-based environmental plan should be considered for future developments [20].

As it has been discussed earlier, green spaces are often unevenly distributed in cities, so some people may lack the right to equally enjoy ecological and cultural benefits provided by the vegetation [21, 22]. Li et al. [23] utilized Google Street View to examine the relationships between the spatial distributions of residential street greening and certain socioeconomic variables in different neighborhoods of Hartford, Connecticut, concluding that people with different social conditions have different amounts of street greening in their living environments. It was carried out a large-scale spatial analysis of the relationship between urban greening and socioeconomic variables in the Portland metropolitan area and conclude that vegetation cover was strongly correlated with a number of phenomena, including population density, housing age, income and ethnicity etc. Bertrand [24] analyzed the spatio-temporal variation, scope and distributional inequities associated with urban green space in Kumasi, Ghana and come to the result that the Gini index for vegetation cover was 0.26 which reflected green space is unevenly distributed in Kumasi.
Similarly, Y [25] has examined spatial regression to study relationship between green space supply and regional socio-demographics in Shenzhen, China and demonstrated inequalities in green space supply. Senetra A. et al. [26] used the city of Tczew in northern Poland as an example to determine the spatial distribution, influence and quality of urban green spaces and the results of the analysis revealed that managed green spaces are unevenly distributed and not all residents have equal access to high-quality public green spaces. Such uneven green space distribution may lead to what is termed environmental injustice [27-30].

Set against the background of further immigration, Kabisch and Haase [31]. analyzed urban green space supply in Berlin to study the relationship of distributional inequities between urban green spaces and population and conclude that successful urban green space planning should provide equal access to high quality green spaces for all residents to achieve sustainable development [31]. Jennifer et al. [32] reviewed the literature on urban green space in Britain and America and compared efforts to green US and Chinese cities and found that most studies revealed that the distribution of urban green space often benefits predominantly White and more affluent communities and the acquisition of is therefore increasingly recognized as an environmental justice issue. Simin and Elizabeth [33] seek to move the debate forward by developing a pluralistic understanding of justice to identify when an uneven distribution of urban greenspace could be considered an environmental injustice and deem that the impact of a deficiency (lack or poor quality) of greenspace is likely to be more felt in socially deprived communities. Poor health conditions and widespread environmental inequalities exist among black and minority ethnic groups, including poor access to urban green space and the poor quality of its provision. Roe et al. [34] employed household questionnaires to study the relationship between general health and predictors including individual, social and physical environmental etc. in deprived white British and black and minority ethnic groups living in ethnically diverse cities in England and their results are discussed from the differences in use and cognition of urban green space among different ethnic groups and they conclude that the UK's health and recreation policy needs to pay more attention to the provision of local green space in poor black and minority ethnic communities since this can play an important role in helping to address the health inequalities experienced by these groups [34]. Henry et al. [35] have explored the supply of urban green space by incorporating geo-coded household data from the German Socio-Economic Panel and census population data with geo-coded data on land use from the European Urban Atlas for German major cities with more than 100.000 inhabitants. Henry et al. [35] developed national indicators for household and individual levels of urban green space supply and environmental inequalities in Germany and the findings presented in the form of Gini 
coefficient shows an unequal distribution of green space supply within cities [35]. Viniece et al. [36] concluded that as an amenity or space that can potentially support the quality of the environmental, social, and health of cities, urban green space has also been at the forefront of modern environmental justice discussions. Viniece et al. [36] stated that inequality in urban green space is often associated with race, ethnicity and many other indicators of socioeconomic and environmental inequality. Such inequities lead to reduced access to ecosystem services from green space for marginalized groups and exacerbate health disparities.

In the context of public benefits of green spaces and from the perspective of environmental fairness, this paper attempts to explore the quantitative method of the uniform distribution of urban green space, develop relevant indicators, analyze the uniform distribution of green space under the guidance of Chinese urban planning theory with examples, and put forward suggestions and solutions to the management problems found in the study.

\section{Material and Methods}

Hezhuang town (Fig. 1), longitude and latitude of $113^{\circ} 46^{\circ} \mathrm{E}, 34^{\circ} 23^{\circ} \mathrm{N}$, is located in the East of Xinzheng city, Henan province, with a planned total land area of $12.80 \mathrm{~km}^{2}$. In the plan, it is positioned as the industrial agglomeration region of Xingang in the Henan province, which is an important base for the central plains city group to undertake the industrial transfer in the east, mainly developing the leading industries such as grain and oil storage, transportation, processing and electronics.

Xudian town (Fig. 1), longitude and latitude of $113^{\circ} 47^{\circ} \mathrm{E}, 34^{\circ} 29^{\circ} \mathrm{N}$, is located in the northeast of Xinzheng city, Henan province, with the planned total land area of $22.24 \mathrm{~km}^{2}$. In the plan, it is positioned as important food industry base of Zhengzhou city, clean energy industry base, stone processing and sales base, suburban leisure tourism service center and center town of Xinzheng city.

Lihe town (Fig. 1), longitude and latitude of $113^{\circ} 43^{\circ} \mathrm{E}, 34^{\circ} 21^{\circ} \mathrm{N}$, is located in the South of Xinzheng city, Henan province, with a planned total land area of $6.9 \mathrm{~km}^{2}$. In the plan, it is positioned as the development of building materials, agricultural and sideline products processing based on the industrial and trade town.

The master plan of Hezhuang town (2009-2020), the master plan of Xudian town (2011-2025) and the master plan of Lihe town (2011-2030) are utilized for this study.

This section describes the methodology used for this study. Gini coefficient is an internationally used index to measure the income gap between residents of a country or region. The maximum value is " 1 " and the minimum value is " 0 ". The closer the Gini coefficient is to 0 , the more evenly the income is distributed. Gini coefficient method is used to calculate uniformity of urban green space distribution, and three indices are derived, namely: horizontal distribution index, vertical structure index and composite structure index of green space, respectively. These three indices can be understood as the Gini coefficient of green space distribution in cities calculated from the distribution angle of the ratio of green space, the vertical structure ratio of green space and their overlapping distribution. In combination with Gini coefficient to evaluate the uniformity, the values of these three indicators can be used to judge the uniformity of vegetation distribution in the city from the perspectives of horizontal, vertical and composite, and further to provide a basis for judging the urban environment fairness.

\section{Horizontal Distribution Index of Green Space}

Town master plan is marked off into several subregions and calculated the ratio of green space in each sub-region, among which the sub-region reaching the standard of the ratio of green space is the qualified one. The value of horizontal distribution index of
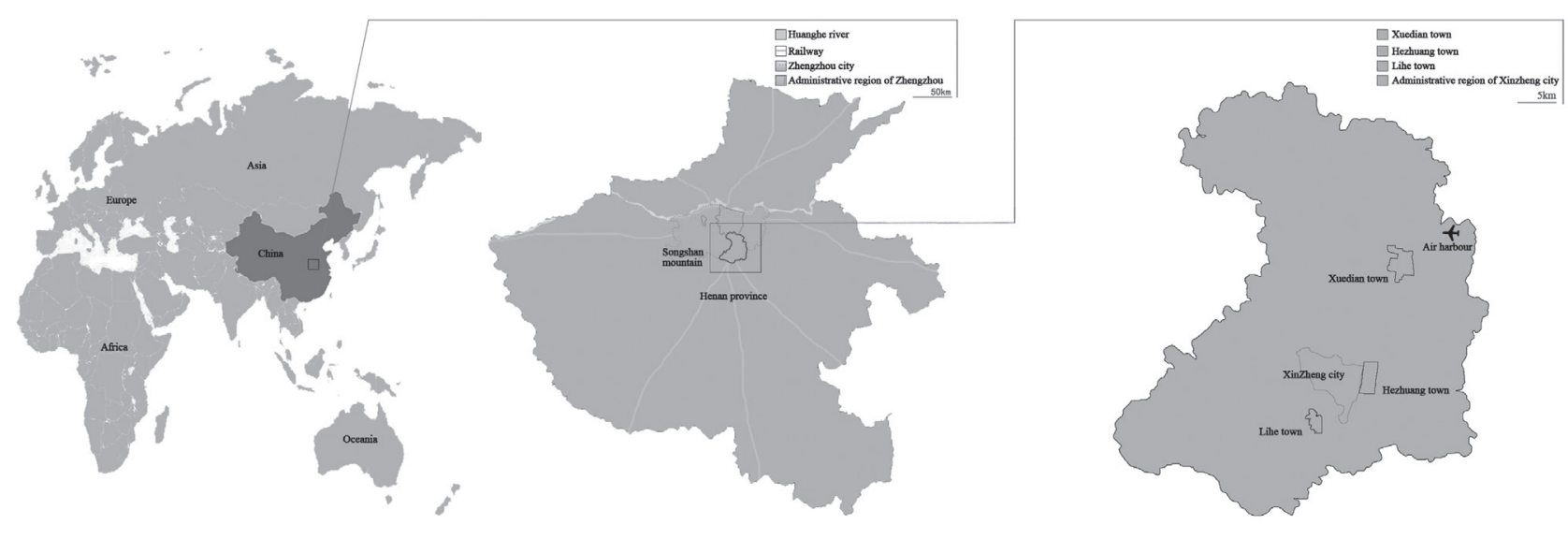

Fig. 1. Location of Hezhuang town, Xuedian town and Lihe town. 
the sub-regions reaching the standard of the ratio of green space in the whole planning region is obtained through Gini coefficient. This value represents the horizontal distribution index of green space. Compared with Gini Coefficient evaluation criteria, we can judge the uniform distribution of the sub-areas whose green space ratio reaches the standard in the planning area.

\section{Vertical Structure Index of Green Space}

In the division diagram of the same town planning region, the vertical structure ratio of green space in each sub-region is calculated and the sub-regions whose vertical structure ratio reaches the standard are the qualified ones. The Gini coefficient is used to quantify the value of vertical structure index of the qualified sub-regions in the whole planning region. This value represents the vertical structure index of green space. Compared with Gini Coefficient evaluation criteria, we can judge the uniform distribution of the sub-areas whose vertical structure ratio reaches the standard in the planning area.

\section{Composite Structure Index of Green Space}

In the division diagram of the same town planning region, the sub-regions whose green area to land ratio and green space vertical structure ratio both reach the standard are regarded as qualified ones, and the Gini coefficient is used to quantify the value of composite structure index of the qualified sub-regions in the whole planning region. This value represents the composite structure index of green space. Compared with Gini coefficient evaluation criteria, we can judge the uniform distribution of the sub-areas whose ratios of green space and vertical structure both reaches the standard in the planning area.

The details of model developed for this study is described in this section. Delimiting the virtual measuring lines to the town planning region and the planning region is divided into equal units and each unit is represented by a sign. The selected objects in each sub-region were calculated one by one, and the qualified and unqualified sub-regions were marked respectively to obtain the distribution pattern diagram of the qualified sub-regions of the objects. The corresponding Lorenz curve and Gini coefficient were obtained through quantitative statistics of the pattern, and the distribution pattern of green space in the town was assessed.

\section{Calculation of Horizontal Distribution Index of Green Space}

The green space ratio in each sub-region delimited by the virtual measuring lines is calculated and expressed in the model grid as a numerical value. According to the standard of green space ratio, the subregions reaching the standard in the grid are marked (the sub-regions failing to reach the standard are not marked), and the distribution pattern diagram of the sub-regions reaching the standard in the planning region is obtained.

By dividing the grid into groups of the same number according to the numbering order, the grid number of each group and the grid number of the sub-region within the group where the horizontal distribution of green space reaches the standard are counted. The datum are arranged from small to large according to the number of grids in the sub-region where the green space ratio reaches the standard, the cumulative value and percentage cumulative value of the grid number and the number of grids in the sub-region where the green space ratio reaches the standard are calculated. The abscissa represents the cumulative percentage of grid number, and the ordinate represents the percentage of grid number in the sub-region where the green space ratio reaches the standard. The origin of coordinates have been determined, the horizontal and vertical coordinate data on the coordinate paper have been marked, connected all points with smooth curves to obtain Lorenz curve according to which the Gini coefficient is calculated and the horizontal distribution index of green space is obtained.

\section{Calculation of Vertical Structure Index of Green Space}

The vertical structure of green space refers to the three-layer combination structure of green space including arbors, shrubs and grasses. The vertical structure of green space reaches the standard means the ratio of green space area with three-layer structure of arbors, shrubs and grasses to the total green space area reaches the standard. The sub-regions where the green space vertical structure ratio reaches the standard are calculated, and the distribution pattern diagram of the sub-regions where the green space vertical structure reaches the standard is obtained. Draw the Lorenz curve of distribution of green space vertical structure reaching the standard, and calculate the green space vertical structure index.

\section{Calculation of Composite Structure Index of Green Space}

Sub-regions where green space composite structure reaching the standard simultaneously meet the green space ratio and green space vertical structure ratio both reach the standard. The distribution pattern diagram of the sub-regions where the green space ratio reaches the standard is superimposed on green space vertical structure ratio reaches the standard, and the distribution pattern diagram of the sub-regions where the green space composite structure ratio reaches the standard is obtained by excluding the sub-regions where the noncomposite structure reaches the standard. Draw the Lorenz curve of distribution of green space composite 


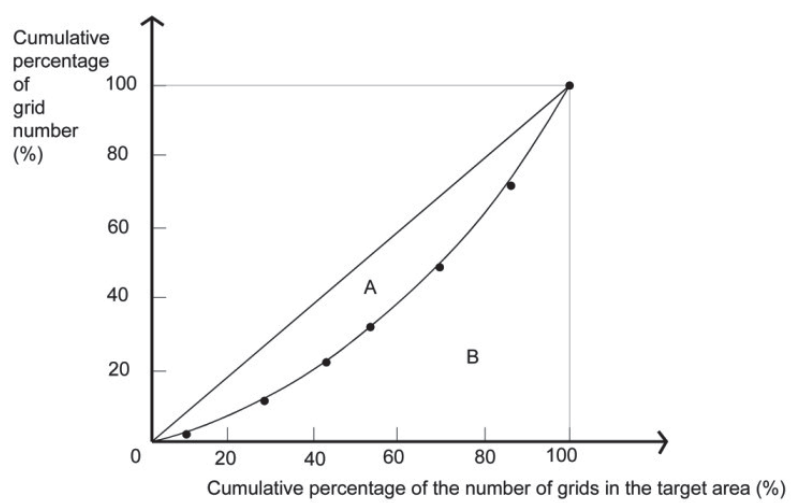

Supplementary Fig. 1. Reference figure for Gini coefficient calculation based on Lorenz curve.

structure reaching the standard, and calculate the green space composite structure index.

Calculation of Gini coefficient based on lorenz curve: The Gini coefficient can be expressed as the ratio of area $\mathrm{A}$ of the region between the 45-degree line and the Lorenz curve to area $(\mathrm{A}+\mathrm{B})$ of the region under the 45-degree line, namely the Gini coefficient $\mathrm{G}=\mathrm{A} /(\mathrm{A}+\mathrm{B})$ (Supplementary Fig. 1).

\section{Results}

The results of this study are presented in this section. Chinese urban green space system planning needs to meet the standard of " 300 meters for a little garden and 500 meters for a larger garden" and it is a basic requirement for all cities to have $30 \%$ green space.
$300 \mathrm{~m}$ virtual measuring line grid has been delimited, and the standard value of green space ratio are set at $0.30[37,38]$. The results are presented below.

\section{Green Space Distribution Indices of Hezhuang Town}

The standard value of green space vertical structure ratio in Hezhuang town was calculated to be 0.58 .

The green space ratio and vertical structure ratio in each grid have been calculated in the grid numbering diagram of Hezhuang town. According to the standard value, the distribution pattern of sub-regions where green space ratio reaching the standard and the distribution pattern of sub-regions where vertical structure ratio reaching the standard in the planning region were drawn. After superposition, the distribution pattern diagram of sub-regions where composite structure reaching the standard in the main urban region was obtained. There were 145 effective grids in the planning region of Hezhuang town, which were divided into 12 groups with 12 grids in each group and the last grid was omitted.

According to the distribution pattern of subregions reaching the standard in green space horizontal distribution planning, the collation and ranking table of green space horizontal distribution planning datum was obtained (Table 1). Lorenz curve of the sub-regions were drawn, where the horizontal distribution planning of green space reaches the standard in Hezhuang town (Fig. 2a), and their green space horizontal distribution index equals 0.23 .

According to the distribution pattern of sub-regions reaching the standard in green space vertical structure

Table 1. Collation and ranking table of horizontal distribution planning data of green space in Hezhuang town.

\begin{tabular}{|c|c|c|c|c|c|c|}
\hline $\begin{array}{l}\text { Group } \\
\text { number }\end{array}$ & $\begin{array}{c}\text { Grids } \\
\text { quantity }\end{array}$ & $\begin{array}{l}\text { Cumula- } \\
\text { tive grids } \\
\text { quantity }\end{array}$ & $\begin{array}{l}\text { Cumulative } \\
\text { percentage of } \\
\text { grids quantity } \\
(\%)\end{array}$ & $\begin{array}{c}\text { Grids quantity } \\
\text { of sub-region reaching } \\
\text { the standard of green area } \\
\text { to land ratio }\end{array}$ & $\begin{array}{l}\text { Cumulative quantity } \\
\text { of grids where } \\
\text { sub-region reaches } \\
\text { the standard }\end{array}$ & $\begin{array}{l}\text { Cumulative quantity } \\
\text { percentage of grids where } \\
\text { sub-region reaches } \\
\text { the standard }(\%)\end{array}$ \\
\hline 1 & 12 & 12 & 8.33 & 1 & 1 & 1.72 \\
\hline 2 & 12 & 24 & 16.67 & 3 & 4 & 6.90 \\
\hline 3 & 12 & 36 & 25.00 & 4 & 8 & 13.79 \\
\hline 4 & 12 & 48 & 33.33 & 4 & 12 & 20.69 \\
\hline 5 & 12 & 60 & 41.67 & 4 & 16 & 27.59 \\
\hline 6 & 12 & 72 & 50.00 & 4 & 20 & 34.48 \\
\hline 7 & 12 & 84 & 58.33 & 4 & 24 & 41.38 \\
\hline 8 & 12 & 96 & 66.67 & 4 & 28 & 48.28 \\
\hline 9 & 12 & 108 & 75.00 & 6 & 34 & 58.62 \\
\hline 10 & 12 & 120 & 83.33 & 8 & 42 & 72.41 \\
\hline 11 & 12 & 132 & 91.67 & 8 & 50 & 86.21 \\
\hline 12 & 12 & 144 & 100.00 & 8 & 58 & 100.00 \\
\hline
\end{tabular}




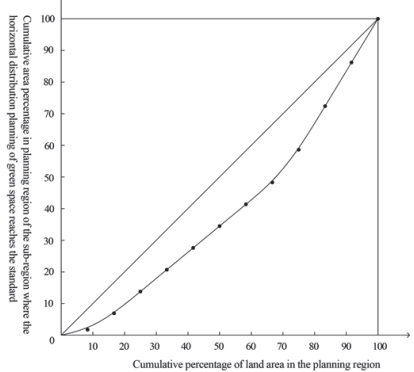

a)

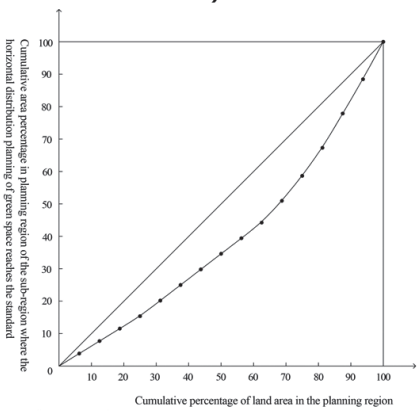

d)

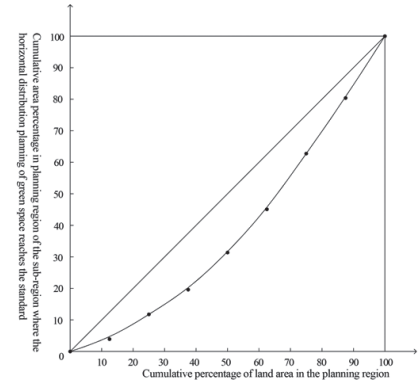

g)

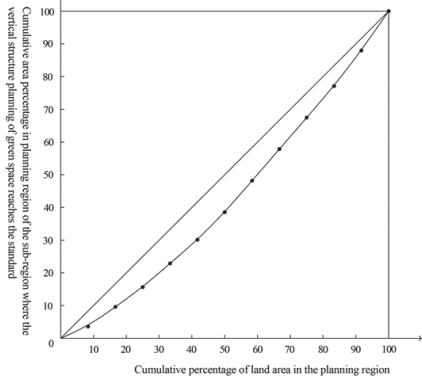

b)

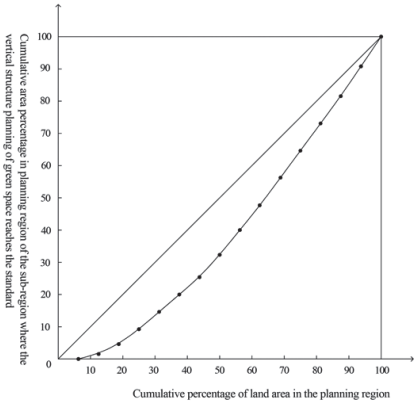

e)

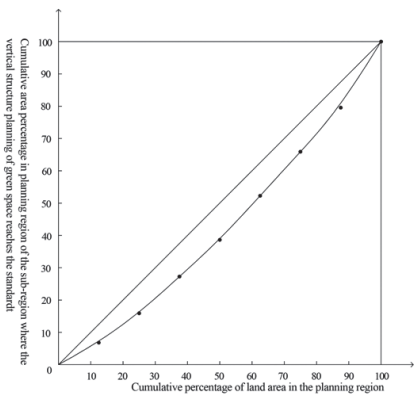

h)

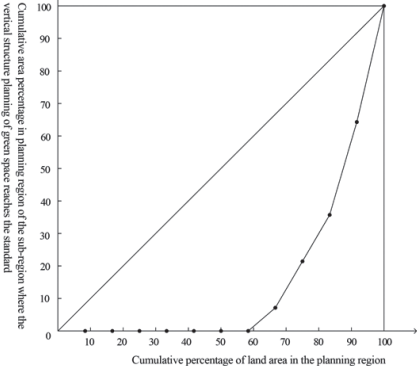

c)

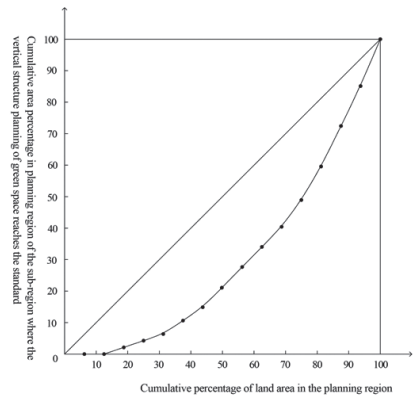

f)

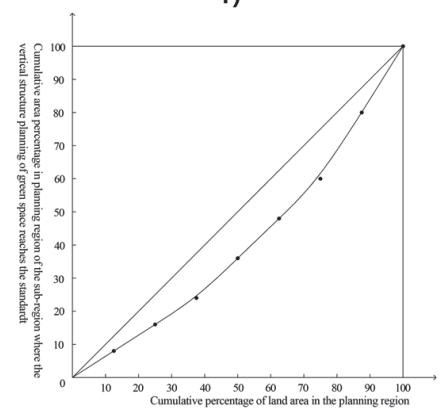

i)

Fig 2. Lorenz curves of green space distribution in Hezhuang town, Xuedian town and Lihe town respectively. 2a. Lorenz curve of the sub-region where the horizontal distribution planning of green space reaches the standard in Hezhuang town. $2 b$. Lorenz curve of the sub-region where the vertical structure ratio of green space reaches the standard in Hezhuang town. 2c. Lorenz curve of the sub-region where the composite structure planning of green space reaches the standard in Hezhuang town. 2d. Lorenz curve of the sub-area where the horizontal distribution planning of green space reaches the standard in Xuedian town. 2e. Lorenz curve of the sub-region where the green space vertical structure ratio reaches the standard in Xuedian town. $2 \mathrm{f}$. Lorenz curve of the sub-region where the green space composite structure planning reaches the standard in Xuadian town. 2g. Lorenz curve of the sub-area where the horizontal distribution planning of green space reaches the standard in Lihe town. $2 \mathrm{~h}$. Lorenz curve of the sub-region where the green space vertical structure ratio reaches the standard in Lihe town. 2i. Lorenz curve of the sub-region where the green space composite structure planning reaches the standard in Lihe town.

planning, the collation and ranking table of green space vertical structure planning datum was obtained (Table 2). Lorenz curve of the sub-regions were drawn, where the vertical structure ratio of green space reaches the standard in Hezhuang town (Fig. 2b), and its green space vertical structure index equals 0.15 .

According to the distribution pattern of sub-regions reaching the standard in green space composite structure planning, the collation and ranking table of green space composite structure planning datum was obtained (Table 3). Lorenz curve of the sub-regions, where the composite structure planning of green space reaches the standard in Hezhuang town (Fig. 2c), and its green space composite structure index equals 0.70 .

\section{Green Space Distribution Indices of Xuedian Town}

The standard value of green space vertical structure ratio in Xuadian town has been calculated to be 0.61 . There were 256 effective grids in the planning region of Xudian town, which were divided into 16 groups with 16 grids in each group.

Lorenz curve of the sub-regions were drawn, where the horizontal distribution planning of green space 
Table 2. Collation and ranking table of vertical structure planning data of green space in Hezhuang town.

\begin{tabular}{|c|c|c|c|c|c|c|}
\hline $\begin{array}{c}\text { Group } \\
\text { number }\end{array}$ & $\begin{array}{c}\text { Grids } \\
\text { quantity }\end{array}$ & $\begin{array}{l}\text { Cumulative } \\
\text { grids quantity }\end{array}$ & $\begin{array}{l}\text { Cumulative } \\
\text { percentage of grids } \\
\text { quantity } \\
(\%)\end{array}$ & $\begin{array}{c}\text { Grids quantity of } \\
\text { sub-region reaching } \\
\text { the standard of vertical } \\
\text { structure ratio }\end{array}$ & $\begin{array}{l}\text { Cumulative quantity of } \\
\text { grids where sub-region } \\
\text { reaches the standard }\end{array}$ & $\begin{array}{l}\text { Cumulative quantity } \\
\text { percentage of grids } \\
\text { where sub-region } \\
\text { reaches the standard }(\%)\end{array}$ \\
\hline 1 & 12 & 12 & 8.33 & 3 & 3 & 3.61 \\
\hline 2 & 12 & 24 & 16.67 & 5 & 8 & 9.64 \\
\hline 3 & 12 & 36 & 25.00 & 5 & 13 & 15.66 \\
\hline 4 & 12 & 48 & 33.33 & 6 & 19 & 22.89 \\
\hline 5 & 12 & 60 & 41.67 & 6 & 25 & 30.12 \\
\hline 6 & 12 & 72 & 50.00 & 7 & 32 & 38.55 \\
\hline 7 & 12 & 84 & 58.33 & 8 & 40 & 48.19 \\
\hline 8 & 12 & 96 & 66.67 & 8 & 48 & 57.83 \\
\hline 9 & 12 & 108 & 75.00 & 8 & 56 & 67.47 \\
\hline 10 & 12 & 120 & 83.33 & 8 & 64 & 77.11 \\
\hline 11 & 12 & 132 & 91.67 & 9 & 73 & 87.95 \\
\hline 12 & 12 & 144 & 100.00 & 10 & 83 & 100.00 \\
\hline
\end{tabular}

Table 3. Collation and ranking table of composite structure planning data of green space in Hezhuang town.

\begin{tabular}{|c|c|c|c|c|c|c|}
\hline $\begin{array}{c}\text { Group } \\
\text { number }\end{array}$ & Grids & Cuantity & $\begin{array}{c}\text { Cumulative } \\
\text { grids quantity } \\
\text { percentage of grids } \\
\text { quantity } \\
(\%)\end{array}$ & $\begin{array}{c}\text { Grids quantity of } \\
\text { sub-region reaching } \\
\text { the standard } \\
\text { of composite structure }\end{array}$ & $\begin{array}{c}\text { Cumulative quantity of } \\
\text { grids where sub-region } \\
\text { reaches the standard }\end{array}$ & $\begin{array}{c}\text { Cumulative quantity } \\
\text { percentage of grids where } \\
\text { sub-region reaches } \\
\text { the standard (\%) }\end{array}$ \\
\hline 1 & 12 & 12 & 8.33 & 0 & 0 & 0.00 \\
\hline 2 & 12 & 24 & 16.67 & 0 & 0 & 0.00 \\
\hline 3 & 12 & 36 & 25.00 & 0 & 0 & 0.00 \\
\hline 4 & 12 & 48 & 33.33 & 0 & 0 & 0.00 \\
\hline 5 & 12 & 60 & 41.67 & 0 & 0 & 0.00 \\
\hline 6 & 12 & 72 & 50.00 & 0 & 1 & 0.00 \\
\hline 7 & 12 & 84 & 58.33 & 0 & 3 & 7.14 \\
\hline 8 & 12 & 96 & 66.67 & 1 & 5 & 21.43 \\
\hline 9 & 12 & 108 & 75.00 & 2 & 9 & 35.71 \\
\hline 10 & 12 & 120 & 83.33 & 3 & 14 & 64.29 \\
\hline 11 & 12 & 132 & 91.67 & 4 & 5 & 100.00 \\
\hline 12 & 12 & 144 & 100.00 & & & 0 \\
\hline
\end{tabular}

reaches the standard in Xuedian town (Fig. 2d), and its green space horizontal distribution index equals 0.22 . Lorenz curve of the sub-regions were drawn, where the green space vertical structure ratio reaches the standard in Xuedian town (see Fig. 2e), and its green space vertical structure index equals 0.25 . Lorenz curve of the sub-regions was drawn, where the green space composite structure planning reaches the standard in Xuadian town (Fig. 2f), and its green space composite structure index equals 0.40 .

\section{Green Space Distribution Indices of Lihe Town}

The standard value of green space vertical structure ratio in Lihe town was calculated to be 0.62 . There were 88 effective grids in the planning region of Lihe town, which were divided into 8 groups with 11 grids in each group.

Lorenz curve is drawn for the sub-regions where the horizontal distribution planning of green space reaches 

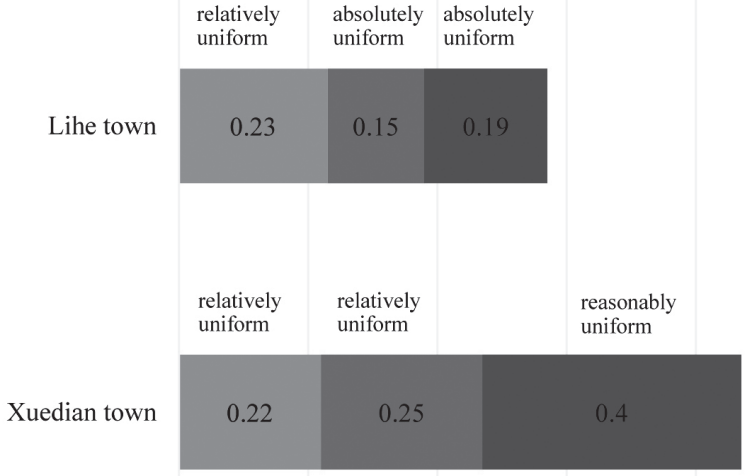

- Horizontal distribution index of green space

- Vertical structure index of green space

- Composite structure index of green space

Fig. 3. Comparison chart of green space distribution indices in Hezhuang town, Xuedian town and Lihe town.

the standard in Lihe town (Fig. 2g), and its green space horizontal distribution index equals 0.23 . Lorenz curve is drawn for the sub-regions, where the green space vertical structure ratio reaches the standard in Lihe town (Fig. 2h), and its green space vertical structure index equals 0.15 . Lorenz curve is drawn for the subregions where the green space composite structure planning reaches the standard in Lihe town (Fig. 2i), and its green space composite structure index equals 0.19 .

\section{Interpretation of Green Space Distribution Indices}

According to the provisions of World Bank [39] if the Gini coefficient is lower than 0.2, which implies the absolute average income; 0.2-0.3 denotes the relatively average income; $0.3-0.4$ means the relatively reasonable income; 0.4-0.5 indicates a large income gap; more than 0.5 indicates a great income disparity, respectively.

According to the evaluation standard of Gini coefficient [39, 40], the distribution pattern of green space planning in these three towns is analyzed in Fig. 3. The horizontal distribution indices of green space in the three towns are within the relatively average threshold. The vertical structure indices of Hezhuang town and Lihe town are within the absolute average threshold, while the vertical structure index of Xuedian town is within the relatively average threshold. The green space composite structure index of Hezhuang town is within the threshold range of great disparity, the green space composite index of Xuedian town is within the relatively reasonable threshold, and the green space composite structure index of Lihe town is within the absolute average threshold.
According to the analysis of the research indices, the horizontal and vertical distribution patterns of green space in the three towns are uniform, among which Hezhuang town and Lihe town have the absolutely uniform vertical structure distribution pattern. However, the distribution patterns of the green space composite structure of the three towns are quite different, and the distribution pattern of the green space composite structure of Hezhuang town is very nonuniform (centralized distribution), the distribution pattern of the green space composite structure of Xuedian town is reasonably uniform, and the distribution pattern of the green space composite structure of Lihe town is absolutely uniform.

Based on the experimental study, we find that:

(1) Green space distribution indices, green space vertical structure index and green space composite structure index of Hezhuang town are $0.23,0.15$ and 0.70 , respectively;

(2) Green space distribution indices, green space vertical structure index and green space composite structure index of Xuedian town are $0.22,0.25$ and 0.40 , respectively;

(3) Green space distribution indices, green space vertical structure index and green space composite structure index of Lihe town are $0.23,0.15$ and 0.19 , respectively.

The indices reveal that the horizontal and vertical distribution patterns of green space in the three towns are even.

The distribution pattern of the green space composite structure of Hezhuang town is very uneven (centralized distribution), Xuedian town is reasonably even, and Lihe town is absolutely even. 

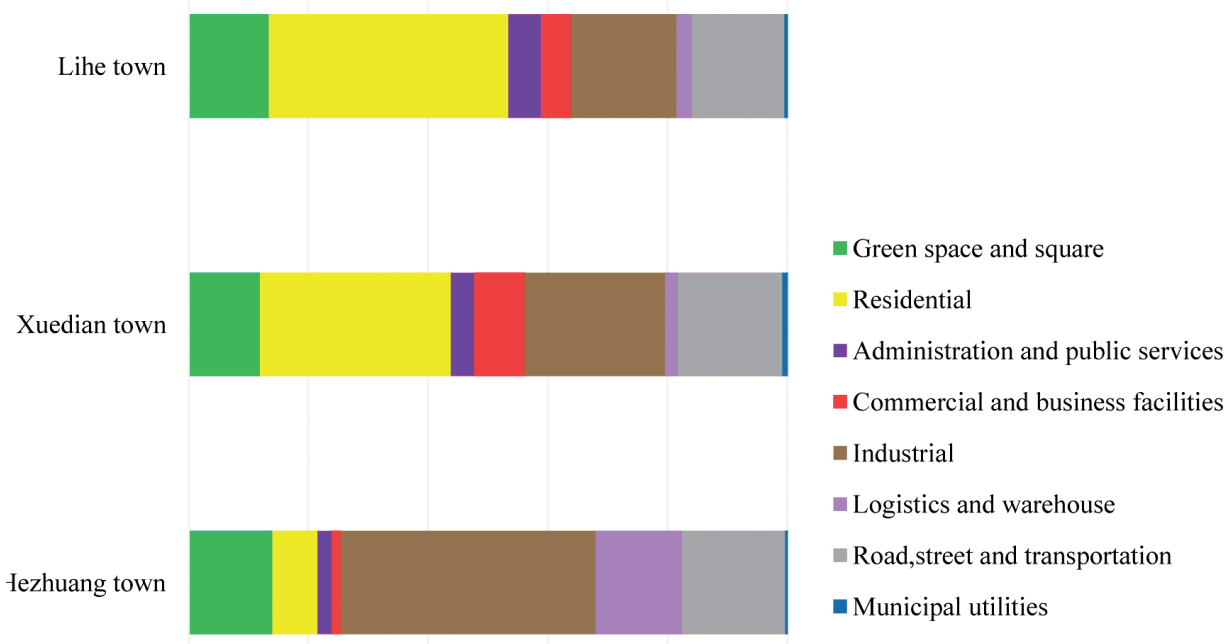

$0 \% \quad 20 \% \quad 40 \% \quad 60 \% \quad 80 \% \quad 100 \%$

Fig. 4. Comparison chart of proportional structures of planned land use in Hezhuang town, Xuedian town and Lihe town.

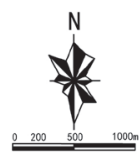

Sub-standard sub-regions

Sub-regions of green land ratio reaching the standard

Sub-regions of vertical structure ratio reaching the standard

Sub-regions of composite structure reaching the standard

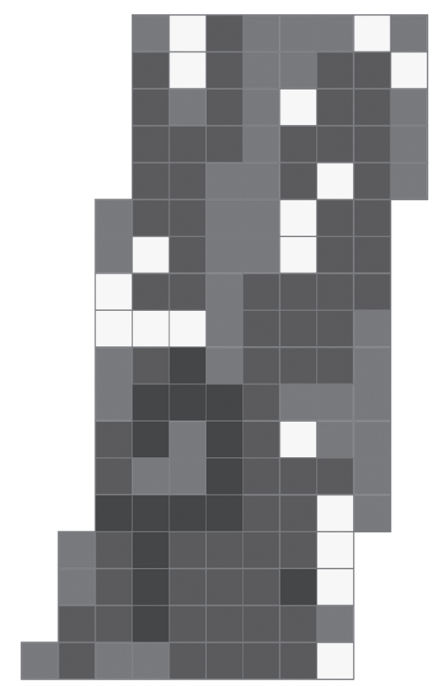

Fig. 5. Planning distribution graph of green space reaching the standard in Hezhuang town.

\section{Discussion}

\section{Longitudinal Analysis of Individual} Towns

The reason that the land distribution of green area to land ratio reaching the standard and the land distribution of vertical structure reaching the standard in Hezhuang town are very uniform (Fig. 3) while the land distribution of composite structure reaching the standard is very nonuniform (centralized distribution) is that as a provincial-level industrial agglomeration, industrial land in Hezhuang town occupies the highest proportion of development land, and industrial land has become an obvious advantage (Fig. 4).

China's national and local standards have relatively low requirements on the green space ratio of industrial land and relatively high requirements on the vertical structure ratio (Table 4), so the distribution of

Table 4. Reference standards of green area to land ratio and vertical structure ratio in urban development land planning $(32,38,40,41$, 42).

\begin{tabular}{|c|c|c|c|}
\hline Codes & Names & $\begin{array}{c}\text { Green area to land ratio reaching the } \\
\text { standard }\end{array}$ & $\begin{array}{c}\text { Vertical structure ratio reaching the } \\
\text { standard }\end{array}$ \\
\hline G1 & Green space & 0.70 & 0.42 \\
\hline R & Residential & 0.30 & 0.70 \\
\hline A & Administration and public services & 0.35 & 0.60 \\
\hline B & Commercial and business facilities & 0.20 & 0.60 \\
\hline M & Industrial & 0.20 & 0.60 \\
\hline W & Logistics and warehouse & 0.20 & 0.60 \\
\hline S & Road, street and transportation & 0.20 & 0.60 \\
\hline U & Municipal utilities & 0.30 & 0.60 \\
\hline
\end{tabular}




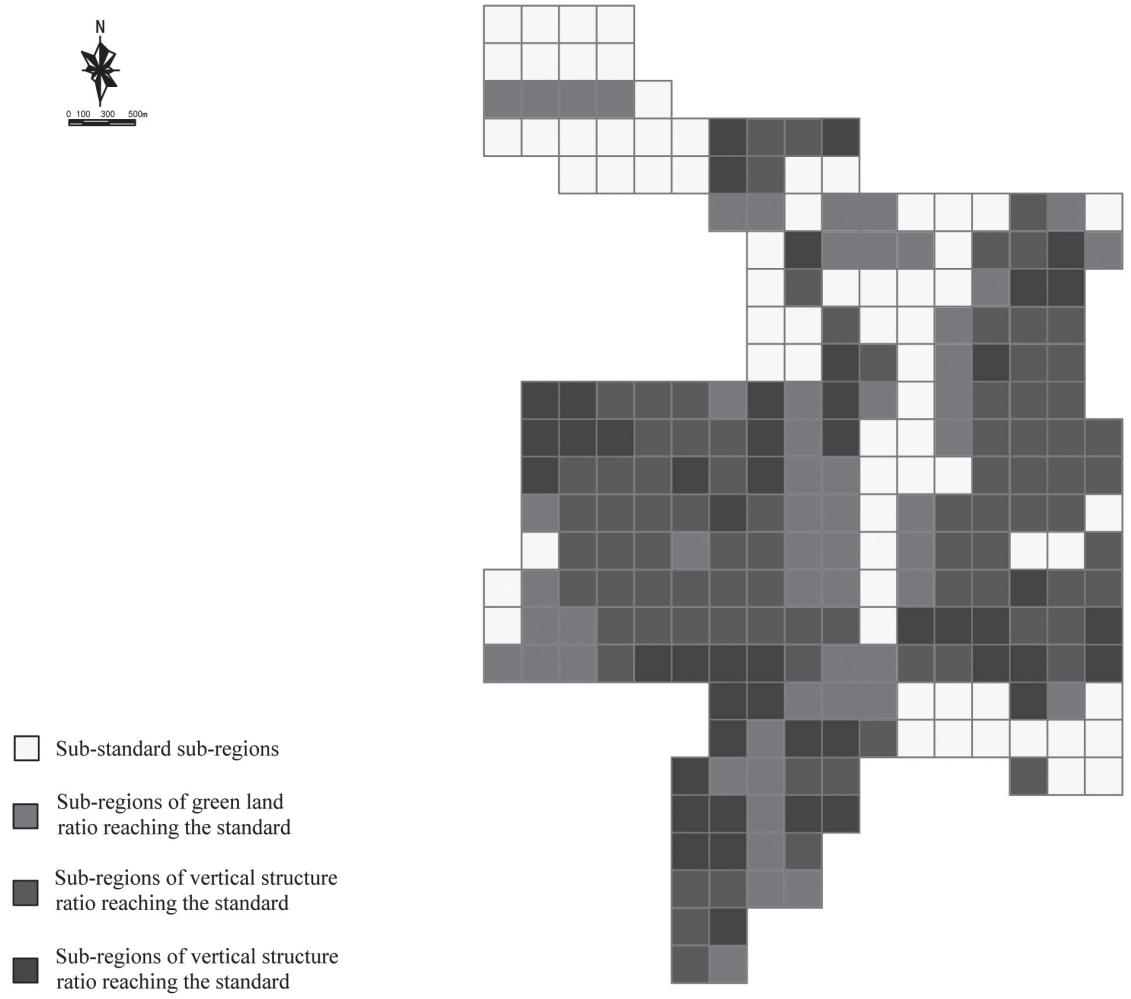

Fig. 6. Planning distribution graph of green space reaching the standard in Xuedian town.

industrial land dominates the distribution indices of green space in Hezhuang town. By comparison with the master plan of Hezhuang town, the distribution of green space whose composite structure reaching the standard in Hezhuang town (Fig. 5) is consistent with the distribution of residential land, indicating that the distribution of residential land has an obvious impact on the distribution of green space whose composite structure reaches the standard.

The reason that the land distribution of green space ratio reaching the standard and the land distribution of vertical structure reaching the standard in Xuedian town are very uniform (Fig. 3) while the land distribution of composite structure reaching the standard is reasonably uniform is that as the central town of Xinzheng, Xuedian town has a similar proportion of residential land and industrial land, and a more balanced land development, with no obvious advantages in land use classes (Fig. 4). China's national and local standards have relatively low requirements on the green space ratio of industrial land and relatively high requirements on the vertical structure ratio (Table 4), and have relatively high requirements both on the green space ratio and the vertical structure ratio of residential land, so the difference between residential land and industrial land leads to the fact that the distribution uniform pattern of green space with composite structure reaching the standard in Xuedian town is not as good as the uniform pattern of the horizontal distribution and the vertical structure distribution of green space (Fig. $6)$.
The reason that the land distribution of green space ratio reaching the standard, the land distribution of vertical structure reaching the standard and the land distribution of composite structure reaching the standard in Lihe town are all very uniform (Fig. 3 and Fig. 7) is that residential land in Lihe town occupies the highest proportion of construction land, and has become an obvious advantage (Fig. 4). China's national and local standards have relatively high requirements

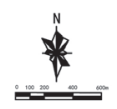

Sub-standard sub-regions

Sub-regions of green land ratio reaching the standard

Sub-regions of vertical structure ratio reaching the standard

Sub-regions of composite structure reaching the standard

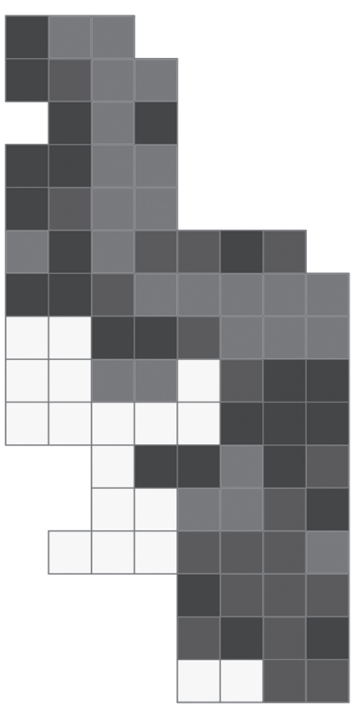

Fig. 7. Planning distribution graph of green space reaching the standard in Lihe town. 
both on the green space ratio and the vertical structure ratio of residential land, and Lihe town is an ordinary town of Xinzheng city, and moreover, the geographical features and development environment of Lihe town have no objective restrictions on the distribution of residential land, so the distribution of residential land dominates the distribution indices of green space in Lihe town (Fig. 7).

\section{Horizontal Analysis of the Three Towns}

The town nature dominates the development land structure and the development land structure dominates the distribution pattern of town green space.

In China, the structure of urban development land is standardized (Table 5), while the structure of planned urban development land in industrial and mining cities, scenic and tourist cities and other cities with special conditions can be specifically determined according to the actual situation [41]. Hezhuang town, Xuedian town and Lihe town have different planning characters. Hezhuang town is a provincial industrial agglomeration region, Xuedian town is a central town of Xinzheng city, and Lihe town is a common town of Xinzheng city. According to the differences in town development positioning, the structural characteristics of planned development land in the three towns are significantly different (Fig. 3). Green land and square land, residential land, industrial land, road and traffic facilities land are the main types of land use in the three towns, among which green land and square land and road and traffic facilities land have a small difference in the proportion of planned land use, while residential land and industrial land have a large difference in the proportion of planned land use. Lihe town has the largest proportion of residential land, while Hezhuang town has the smallest. Hezhuang town has the largest proportion of industrial land, while Lihe town has the smallest. The proportion of logistics and storage land in Hezhuang town is the largest among the three towns, and much larger. After comparing the land use structure of the three towns, residential land and industrial land present a reciprocal relationship in the whole town development land structure, and the ebb and flow relationship is dominated by planning

Table 5. Stipulations on the proportion of urban development land in China.

\begin{tabular}{|c|c|}
\hline Land types & $\begin{array}{c}\text { Proportion of urban } \\
\text { construction land (\%) }\end{array}$ \\
\hline Residential & $25.0-40.0$ \\
\hline $\begin{array}{c}\text { Administration and public } \\
\text { services }\end{array}$ & $5.0-8.0$ \\
\hline Industrial & $15.0-30.0$ \\
\hline Road, street and transportation & $10.0-25.0$ \\
\hline Green space and square & $10.0-15.0$ \\
\hline
\end{tabular}

nature of them, and due to the different character of towns, the logistics and storage land may also have an overall structural impact on the development land as a secondary factor.

Comparison of the change of green space distribution indices in three towns in Chinese urban planning system, the change of development land structure has not yet affected the uniform distribution pattern of the horizontal distribution and the vertical structure of green space, but has a great impact on the distribution pattern of the composite structure of green space. With the change of town nature, the structure of construction land changes accordingly, and the distribution pattern of town green space is affected, especially the composite structure distribution pattern of town green space is the most affected. Among them, the structures of residential land and industrial land are the main factors influencing the distribution pattern of town green space planning; the land for logistics and storage may become the secondary factor influencing the distribution pattern of town green space planning; the influence of other development land on the distribution pattern of town green space planning is relatively stable.

The value of urban green space distribution indices can be adjusted through the distribution pattern of park green space, protective green space and square land and can also be adjusted through the distribution pattern of other development land. Generally speaking, it is relatively easy to adjust the planning distribution indices of green space through the adjustment of the distribution pattern of park green space, protective green space and square land.

Analysis of town green space planning and development:

Green space planning indicators in town development land (Table 4) and proportion of town development land (Table 5) lead the research on the distribution pattern of town green space. However, relevant national regulations in China have not clearly put forward requirements on the green space ratio and vertical structure ratio of square land and protective green space [41, 42], nor on the vertical structure ratio of all eight types of urban construction land [41]. The lack of relevant national norms is not conducive to town green space planning, construction, management, and research etc.

For this study, relevant indicators have been sorted out in combination with local standards and norms, and it is suggested to promote the formulation and implementation of green area to land ratio standards for square land and protective green space and vertical structure ratio standards for eight types of urban development land as soon as possible, so as to improve the urban green space planning system.

The difference of green space distribution in three towns is the objective reflection of urban planning and theory in different cities and towns, which shows that urban planning norms and theory in China play an important guiding role in urban planning. So by further 
analysis, four conclusions are made and one advice is drawn through this investigation.

Through the four conclusions it has been inferred that it is generally easy to adjust the planning distribution indices of green space by adjusting the distribution pattern of park green space, protective green space and square land. However, it is relatively difficult to adjust the distribution indices of green space planning through adjusting the distribution pattern of other development lands such as residential land, land for public administration and public service, land for commercial service facilities, land for industry, land for logistics and storage, land for road and transportation facilities and land for public facilities.

Currently, there is still a lack of green space planning standards in China's national regulations, so a regulatory policy relevant corollary has been drawn through this investigation, which is given as follows:

Promoting the formulation and implementation of green area to land ratio standards for square land and protective green space and vertical structure ratio standards for all eight types of urban development lands as soon as possible.

The research method of this paper still needs to be further improved from the following aspects:

(1) The establishment of virtual measuring lines is subjective, and the standards of green space and vertical structure ratio need to be formulated by combining the national conditions.

(2) For researchers with a preliminary understanding, the meaning of the three indicators may also need to be improved.

(3) Absolutely uniform distribution of green space is not necessarily conducive to the development of ecological benefits in cities and towns, but the distribution pattern of urban green space must be controlled. The evaluation of these three indicators needs a reasonable threshold evaluation standard, which certainly needs a lot of research and practice results to obtain. Currently, a more reasonable evaluation threshold cannot be found, so the threshold standard of social and economic circles is temporarily adopted to make the whole study more complete.

\section{Conclusions}

This paper concludes that the uniformity of urban green space distribution will affect the environmental justice and social justice. From this perspective, we study the method of quantifying the uniformity of urban green space distribution through the urban planning map. The gird method effectively transforms the two-dimensional raster map into a digital model that can be used for quantitative analysis. It is found that the grid model and Gini coefficient calculation model can be integrated. So the quantifying method which integrates the grid model and Gini coefficient calculation model is used to quantitatively analyze the distribution pattern of town green space from three aspects: horizontal distribution of green space, vertical structure distribution of green space, and composite structure distribution of green space. In order to verify whether this quantitative model can accurately analyze the uniform distribution of urban green space through the urban planning map, three towns of Xinzheng City, Henan Province, China are taken as an example and the uniform distribution of green space is calculated successfully by using their master planning maps. The indexes obtained by this method can be compared in the longitudinal direction of a single town, and the reasons and mechanisms that lead to the urban planning pattern are analyzed through the differences among the horizontal distribution index, vertical structure index and composite structure index of green space, in order to determine the main and secondary reasons that affect the distribution pattern of green space in this town. This method can also be used to compare the distribution indexes of green space between different cities and towns, so as to analyze the causes and mechanisms of different distribution patterns of green space in different cities and towns, and summarize experience for urban green space planning. The proposed model is used to calculate the uniform distribution of green space in the whole town planning and the overall distribution of green space in the whole town can be judged after the results are obtained. If it is not uniform, the urban land distribution can be adjusted according to the planning idea and the obtained qualified and non-conforming sub-regions distribution, in order to make the urban green space distribution reach or approximate to the uniform state based on the Gini coefficient reference standard. So the application of this method also improves the initiative of garden and green space planning in town planning. We have also successfully carried out correlation analysis through examples. These three indexes cannot only be used in the self-examination of urban garden and green space system planning and construction, but also can be used in the supervision of planning and construction status. In this paper, a systematic quantitative and evaluation method is explored, which provides a clear idea for the study of the distribution uniformity of urban green space. Grid method, Lorenz curve and Gini coefficient were used to quantify the distribution of urban green space, establish a model that can be quantified through planning or a high-resolution aerial or remote sensing image, thus the horizontal distribution of green space and the multi-layer structure of vegetation in green space are fully expressed. The self-evaluation of the uniform distribution of green space in cities and towns and the comparative evaluation of the distribution of green space between cities and towns can be realized through the corresponding evaluation criteria. The research methods and indices of this paper provide a basis for the judgment of urban environmental equity, and the research conclusions and suggestions of this paper can provide a reference for 
more equitable and sustainable green space and urban planning.

\section{Acknowledgements}

We would like to thank Bureau of Housing and Urban-rural Planing and Construction of Xinzheng city for providing basic data and planning drawings. We would also like to thank Mr. Yanlong Jiang and Mr. Jiajun Cui for the help in the investigation process.

This work was supported by The Research Project of Henan Province Science and Technology Research Project in 2021 (No.212102310581); Key Projects of Henan Provincial Department of Education in 2021 (21A220002); The Annual Project of Philosophy and Social Science planning of Henan Province in 2020 (No. 2020BSH003); Henan Science and Technology Think tank in 2019 (No. HNKJZK-2019-32B).

\section{Conflict of Interest}

The authors declare no conflict of interest.

\section{References}

1. LUAN B., CHAI M.W., WANG X. Review of development, frontiers, and prospects of green infrastructure. Acta Ecologica Sinica, 37 (15), 5246, 2017.

2. MCCRACKEN D.S., ALLEN D.A., GOW A.J. Associations between urban greenspace and health-related quality of life in children. Preventive Medicine Reports, 3, 211, 2016.

3. TAYLOR L., HOCHULI D.F. Creating better cities: how biodiversity and ecosystem functioning enhance urban residents' wellbeing. Urban Ecosystems, 18 (3), 747, 2015.

4. MICHELL C.K., JAIME M.F., THOMAS M., CHARLES C.B. Urban green space and its impact on human health. International Journal of Environmental Research \& Public Health, 15 (3), 445, 2018.

5. NESBITT L., HOTTE N., BARRON S., COWAN J., SHEPPARD S.R.J. The social and economic value of cultural ecosystem services provided by urban forests in North America: A review and suggestions for future research [J]. Urban Forestry \& Urban Greening, S1618866717300456, 2017.

6. NOWAK D.J., APPLETON. N., ELLIS A., GREENFIELD E. Residential building energy conservation and avoided power plant emissions by urban and community trees in the United States [J]. Urban Forestry \& Urban Greening, 21, 158, 2017.

7. KONDO M.C., LOW S.C., HENNING J., BRANAS C.C. The impact of green stormwater infrastructure installation on surrounding health and safety. American Journal of Public Health, 105 (3), e1, 2015.

8. ROBERTS H.V. Using twitter data in urban green space research: a case study andcritical evaluation. Applied Geography, 81, 13, 2017.

9. DZHAMBOV A.M., DIMITROVA D.D. Elderly visitors of an urban park, health anxiety and individual awareness of nature experiences. Urban Forestry \& Urban Greening, 13 (4), 806, 2014.

10. MIDDLE I., DZIDIC P., BUCKLEY A., BENNETT D., TYE M., JONES R. Integrating community gardens into public parks: an innovative approach for providing ecosystem services in urban areas. Urban Forestry \& Urban Greening, 13 (4), 638, 2014.

11. CETIN M., ADIGUZEL F., GUNGOR S., KAYA E., SANCAR M.C. Evaluation of thermal climatic region areas in terms of building density in urban management and planning for Burdur, Turkey. Air Qual Atmos Health, 12, 1103, 2019.

12. CETIN M. Determining the bioclimatic comfort in kastamonu city. Environmental Monitoring \& Assessment, 187 (10), 1, 2015a.

13. CETIN M. Using GIS analysis to assess urban green space in terms of accessibility: case study in Kutahya, International Journal of Sustainable Development \& World Ecology, 22:5, 420, 2015b.

14. KAYA E., AGCA M., ADIGUZEL F., CETIN M. Spatial data analysis with $r$ programming for environment. Human and Ecological Risk Assessment, 1, 2018.

15. CETIN M. The effect of urban planning on urban formations determining bioclimatic comfort area's effect using satellitia imagines on air quality: a case study of Bursa city. Air Qual Atmos Health, 12, 1237, 2019.

16. CETIN M. Climate comfort depending on different altitudes and land use in the urban areas in Kahramanmaras City. Air Qual Atmos Health, 13, 991, 2020.

17. TSAI W.L., MELISSA R.M., VINIECE J., ORIOL M., HIPP J.A., LEUNG Y.F., MYRON F.F. Relationships between characteristics of urban green land cover and mental health in u.s. metropolitan areas. International Journal of Environmental Research \& Public Health. 15 (2), 340, 2018.

18. RAUTIO N., FILATOVA S., LEHTINIEMI H., MIETTUNEN J. Living environment and its relationship to depressive mood: a systematic review. International Journal of Social Psychiatry. 64 (1), 002076401774458 , 2017.

19. MIN K.B., KIM H.J., KIM H.J., MIN J.Y. Parks and green areas and the risk for depression and suicidal indicators. International Journal of Public Health. 62 (6), 647, 2017.

20. ZHANG J.G., YU Z.W., ZHAO B., SUN R. Links between green space and public health: a bibliometric review of global research trends and future prospects from 1901 to 2019. Environmental Research Letters. Doi 10.1088/17489326/ab7f64, 2020.

21. HALIK M., WELP M., MAMAT Z., ABLIZ A., SHI L. Urban Green Space Accessibility and Distribution Equity in an Arid Oasis City: Urumqi, China. Forests. 11 (690), $1,2020$.

22. XU C., HAASE D., PRIBADI D.O., PAULEIT S. Spatial variation of green space equity and its relation with urban dynamics: A case study in the region of Munich [J]. Ecological Indicators, 93, 512, 2018.

23. LI X.J., ZHANG C.R., LI W.D., KUZOVKINA Y.A. WEINER D. Who lives in greener neighborhoods? The distribution of street greenery and its association with residents' socioeconomic conditions in Hartford, Connecticut, USA. Urban Forestry \& Urban Greening. 14 (4), 751, 2015.

24. BERTRAND N. Urban green space dynamics and distributional equity in Kumasi, Ghana. Esa Living Planet Symposium. 2016. 
25. YOU H. Characterizing the inequalities in urban public green space provision in shenzhen, china. Habitat International. 56, 176, 2016.

26. SENETRA A., KRZYWNICKA I., MIELKE M. Urban Forestry and Urban Greening, Does green space matter? Exploring relationships between green space type and health indicators. Urban Forestry and Urban Greening. 20, 407, 2016.

27. JOHN R.M., PATRICK C., GEOFFREY H.D. Urban forests and social inequality in the pacific northwest. Urban Forestry \& Urban Greening. 16, 188, 2016.

28. DAVOUDI S., BROOKS E. Urban greenspace and environmental justice claims. Justice and Fairness in the City. 2016

29. DOROTHY C.I. A multi-dimensional classification and equity analysis of an urban park system: a novel methodology and case study application. Landscape and Urban Planning. 137, 122, 2015.

30. THOREAU R.T., BRIAN K., NICHOLAS C.C. geographical approach to identifying vegetation-related environmental equity in Canadian cities. Environment \& Planning B: Planning \& Design. Environment and Planning. 37 (6), 1040, 2010.

31. KABISCH N., HAASE D. Green justice or just green? provision of urban green spaces in berlin, germany. Landscape \& Urban Planning.. 122, 129, 2014.

32. JENNIFER R.W., JASON B., JOSHUA P.N. Urban green space, public health, and environmental justice: the challenge of making cities 'just green enough'. Landscape \& Urban Planning. 125, 234, 2014.

33. SIMIN D., ELIZABETH B. Urban greenspace and environmental justice claims. Justice and Fairness in the City. 2016.

34. ROE J., ASPINALL P., WARD T.C. Understanding Relationships between Health, Ethnicity, Place and the Role of Urban Green Space in Deprived Urban Communities. International journal of environmental research and public health. 13 (7), 681, 2016.
35. HENRY W., DENNIS K., JENS K. Access to urban green space and environmental inequalities in germany. Landscape and Urban Planning. 164, 124, 2017.

36. VINIECE J., MATTHEW H.E.M., BROWNING ALESSANDRO R. Urban Green Space at the Nexus of Environmental Justice and Health Equity. Urban Green Spaces-Public Health and Sustainability in the United States. 2019.

37. CJ[193] No.784, Provisions on targets for urban greening planning and construction.

38. JC. No. 166, Guidelines of the ministry of housing and urban-rural development on promoting the healthy development of urban landscaping. 2012.

39. KOHLER T.A., SMITH M.E., BOGAARD A., FEINMAN G.M., PETERSON C.E., BETZENHAUSER A., PAILES M., STONE E.C., PRENTISS A.M., DENNEHY T.J., ELLYSON L.J., NICHOLAS L.M., FAULSEIT R.K., STYRING A., WHITLAM J., FOCHESATO M., FOOR T.A., BOWLES, S. Greater post-Neolithic wealth disparities in Eurasia than in north America and Mesoamerica. Nature, 551 (7682), 619, 2017.

40. HONG X.J. Acceptable Range and Security Line of Gini Coefficient. Statistical Research, 24 (8), 84, 2007.

41. GB50137-2011, Code for classification of urban land use and planning standards of development land.

42. CJJT 85-2017, Standard for classification of urban green space.

43. CJJ 75-97, Code for planting planning and design on urban road.

44. DBJ440100/T23-2009, Guangzhou code for design of parks.

45. GB50180-2018, Code of urban Residential Areas Planning \& Design.

46. GB51192-2016, Code for the design of public park.

47. HLWB. No. 3, Shanghai unit greening grade evaluation standard. 2006. 